Article

\title{
Configurations and Meanings of Environmental Knowledge: Transitions from the Subjective Experience of Students towards the Intersubjective Experience of $U s$
}

\author{
Antonia Condeza-Marmentini *D and Luis Flores-González * \\ Faculty of Education, Pontificia Universidad Católica de Chile, Santiago 6904411, Chile \\ * Correspondence: aqcondez@uc.cl (A.C.-M.); lmflores@uc.cl (L.F.-G.); Tel.: +56-9-92362178 (A.C.-M.); \\ $+56-2-223547937$ (L.F.-G.)
}

Received: 21 February 2019; Accepted: 5 May 2019; Published: 30 May 2019

\begin{abstract}
Environmental-related education has inherited the concepts of complexity and uncertainty from environmental science. However, these concepts still refer to the environment as an "object" that is separate from the knowing "subject," and not as a phenomenon always inserted into a specific context. With the aim of contributing to generating contextualized environmental knowledge, this article explores the knowledge configuration itinerary regarding environmental issues that was developed by vulnerable students in public secondary schools located in peripheral municipalities of Santiago, Chile. The theoretical framework of complex thinking provides an epistemological opportunity to "read" and understand environmental knowledge within a web of co-determined spheres of social and community knowledge via the transition from "subjective understanding" to "intersubjective knowledge." The knowledge configuration itinerary regarding the environment describes a transition from the sphere of the "self" towards an emplaced "us." It was discussed that the incorporation of place in education is not only a pedagogical means, but also functions as an axis of meaning that highlights the multisemic nature of the environment in its different configurations. It was concluded that an educational project relevant to a global community must be founded upon those differences, as they provide opportunities for configuring knowledge as action and meaning.
\end{abstract}

Keywords: environmental education; complex thinking; place; global education

\section{Introduction}

Environmental education is a field of action and specific knowledge where a multiplicity of cultural variables that influence educational practices has been highlighted. For instance, educational theories, the relationships between teachers and students, the relationships between school and society, and environmental ethics are recognized as key aspects that contribute to the development of particular educational projects [1-7]. Recognizing this multiplicity of contextual factors, environmental education research now portrays the educational phenomenon as an ongoing experience, rather than one fragmented into specific disciplinary frameworks. However, this field of research has also been the subject of strong criticism regarding the reduction of the complexity of its objects of inquiries in ways that produce simplistic and thus almost meaningless conclusions [8-10]. Faced with this reductionist tendency, the framework of complex thinking is understood as an epistemology that considers knowledge as a set of relations and feedback, and not as the product of bilateral relations between a neutral subject and a set of isolated objects. Knowledge is, in this way, a "weave" (complexus) of emerging relationships. 
Morin formulated a paradigm of complexity in "The Method" [11] and aimed to generate the appropriate epistemological conditions to produce intertwined knowledge based on which complex metadisciplinary knowledge (savoir) could be generated, overcoming the idea of a single object of knowledge. From this framework, the paradigm of complexity is nourished by a conjunction of several principles, of which we highlight three key actions for the development of this paper: (1) to situate the interpretation framework on local and global relations; (2) the irreversibility of time and the need to integrate history into any possible description are recognized and integrated, and from such descriptions "explanations" that are not reduced to mere causal relations are constructed; and, (3) the impossibility of isolating and separating any "matter" or problem into basic units is recognized, and the knowledge of any of its elements is related both to the whole and to the parts to which it belongs.

From this perspective of knowledge, phenomenology [12] contributes asserting the philosophical demand to generate a theoretical and methodological shift from the traditional idea of the "object", understood as that which is in front of and independent of us, to the idea of the "phenomenon" of which we are always a part of. The understanding of the phenomenon is always realized in context, that is, in-the-world, and from the "facticity", i.e., of the lived experiences (Lebenswelt) of space and time. These are conceived as intersubjective experiences and not as a set of "things" that are external, separable, and independent from the subject.

Specifically, in the case of disadvantaged schools in Chile, both theoretical frameworks facilitate "reading" the implicit tensions of social phenomena by interpreting the itinerary in which environmental knowledge is configured as a basis for understanding the interests and expectations of students. In the current study, this was carried out through the initiatives and actions that the students themselves developed during our research project.

From a phenomenological and complex thinking perspective, we wanted to include the interests and expectations of students in the development of their own educational practices, and help in the creation of educational approaches that contribute to making visible levels of configuration, from the subjective to the intersubjective, with the aim of showing the dynamics of interrelations between experiences at school and community. With this objective, complex thinking contributes as epistemology, to understanding the action of knowing recursively, both in a given context and from its own configurations of meaning. Consequently it is possible to understand the students' knowledge in relation to their environment as a global and emerging experience.

Based on the aforementioned theoretical background, this research aimed to contribute to the understanding of the dynamic process of co-adaptation between the subjective and institutional views that shape the environment. This is similar to what Güell [11] recognized as the growing tension in modernity between social subjectivity as a principle of change as well as the tendency of institutions to define their own rules, values, and objectives; open-endedness lies in the relationships and orientations of complementarity among these factors (paragraph 14). From this view, each proposed epistemic level—subjective, intersubjective, and operational—appears to be relevant, as they become mediations and phases of themselves, and it allows the emergence of meanings and knowledge.

Therefore, the research question is not one that usually arises, referring knowing how educational contexts are adapted to policies or a curriculum such as Education for Sustainable Development (ESD), but rather, comes from the intersubjective configuration of meanings of the environment between subjects and their relations with the world. The internationalized curriculum corresponds to one of the spheres that mediate such configurations, and from this standpoint, it is possible to avoid the opposition between local and global perspectives that are frequent in some current debates.

Recognizing the diversity of meanings that are given to the environment seems key to the task of finding possibilities for intercultural dialogue considering the educational challenges faced by the global environmental crisis. In relation to such tasks, Sund and Lysgaard [13] argued that research in the field of environmental education requires overcoming the activist motto "take action now" and giving due importance to reflection on the educational perspectives at stake [13] (p. 1612). From our point of view, in order to contribute to the discussion of environmental citizenship that seeks to 
address this crisis from a global perspective, acknowledgment of the knowledge itinerary in its given context is necessary as a first step to pluralize the senses of the environment and generate dialogues that recognize difference as a fundamental principle.

The need to create opportunities for dialogue to articulate local perspectives in the framework of transnational discussion is relevant for exploring various paths to sustainability. This requires an understanding that the curricular orientations of ESD approaches, promoted by international agencies such as UNESCO, contemplate a specific form of thinking locally [14], which is derived from a tradition of environmental knowledge. However, there are many other forms to consider.

Following this line of thought, the purpose of this article is not to recreate a description of Sustainable Development that allows us to act efficiently on a global scale, but to raise a relevant educational question that allows us to approach the local dynamics at length, beginning by interpreting the perspectives of students in a particular context and focusing on our intention to provide meaning to an environment-related education project within that same context.

The remainder of this article is organized as follows. First, the epistemological scope of the theoretical-methodological framework is exposed in the frame of so-called complex thinking. Second, the research questions and methods through which the research was carried out are presented. Third, the itinerary is presented in the students' own "words", highlighting three categories that show the transitions between different spheres of knowledge. Next, the article focuses on the relevance of the place dimension that appears as an axis of meaning in the categories raised, discussing its pedagogical potentialities and the construction of the contextualized educational perspectives of the environment. Finally, the article concludes by affirming that considering a phenomenological and complex thinking perspective of place-based environment knowledge itineraries brings new ways of understanding the local-global relationship, by emphasizing the plurality of meanings of the environment as a requirement for discussion in transnational educational circumstances.

\section{Epistemological Perspectives of Complex Thinking}

As far as the concept of complex thinking is concerned, it is necessary to make some distinctions regarding the use of complexity terminology and some of the tensions generated by its use within and outside of the educational field. According to this perspective, some of the contributions to complexity are collected to clarify our purpose, and conceptual distances are established with other authors who have used the theoretical framework of complexity in a "simple" manner [11].

The concept "complexity" has been used with different objectives and as an adjective (complex) for different phenomena in the fields of hard, biological, and social sciences. In scientific tradition, the framework of complexity has contributed to systems that work in open, far-from-equilibrium dynamics, which are characterized by being non-linear, reflective, irreversible, and self-organized. This theoretical framework contributes to the search for new methodologies that can address complex systems in all their networks as well as emerging relations.

Authors such as Biesta, Osberg, Alhadeff-Jones, Rasmussen, Mason, Morrison, I'Anson, Gough, Fenwick, Simons, Olssen, Gustafson, Davis, Sumara, Iftody, Trueit, and Doll, Jr., among other authors, have "read" the field of education from the lenses of complexity. Biesta and Osberg [15] edited a book whose objective was to explore the significance of complexity theory for education from the point of view of policies of complexity, highlighting the fact that education has to do with the ways of directing, structuring and evaluating human learning, where questions of value and power are simply inevitable [15] (p. 1). These authors stress that questions about values and policies in the field of education are not necessarily present in discussions related to complexity, especially in cases where terminology derived from complex science is used without discretion to allude to multi-variable problems with emergence properties.

Specifically, Biesta $[16,17]$, Osberg and Biesta $[15,18,19]$, and Gough $[10,20]$ used the framework of complexity as opposed to forms of reductionism derived from a mechanistic model that assumes linear thinking. That model is characterized as oriented towards the development of a universal knowledge 
that implies the possibilities of control and predictability, as reflected by the inclusion in the model of "inputs" (policy, curriculum, pedagogy) and "outputs" (learning), which can be measured using the simplified logic of evidence-based learning [19] (p. 6). To visualize some of the epistemological implications of these authors' use of complexity in schooling, they indicated the following:

"A complexity inspired epistemology, we believe, brings forth a different way of thinking about the organization of schooling, which is not another pedagogical version on the representational-presentational spectrum." [19] (p. 224)

Despite these authors sharing objectives and concerns in terms of providing different ways of configuring knowledge and assessing differences, there are also conceptual distances in the way in which each author understands complexity. In relation to the generative metaphors that complexity science contributes to the educational field according to Biesta and Osberg [19], Gough [20] made a pertinent distinction in proposing educational systems as self-organizing systems and affirming that education is a system with this property (p. 4-5). He also stressed the importance of not "'elementarizing' these characteristics to reduce them to the elements of yet another foundational model in which education is (again) over-simplified and distorted", and resisted the idea of understanding complexity as a "new paradigm" for education (p. 4-5). He also emphasized the value of complexity lenses in these terms:

"Reconceiving curriculum, teaching and learning in terms of emergence foregrounds the non-linear, unpredictable and generative qualities of educational processes, and encourages us to value that which is unexpected and/or beyond our control." [20] (p. 1)

In the specific field of environmental education research, Wals and Rodela [21], Wals and Corcoran [22], Wals et al. [23], Lotz-Sisitka et al. [24], and Wals et al. [25] used vocabulary derived from complexity science to refer to sustainability issues. These environmental issues are characterized by "high levels of complexity, ambiguity, controversy, and uncertainty both with respect to what is going on and with respect to what needs to be done", which also suggests that these properties pose new challenges for thinking about learning and pedagogy from a transformative perspective [24](p. 73). Lotz-Sisitka et al. [24] recognized that complexity science has previously questioned the way in which environmental issues are formulated and was critical of how their use could lead to "miseducative" arguments in relation to the aim of transformation towards sustainability. An example of this is the growing use of the concept of "resilience", which the authors discuss as a contribution to the educational field, and in this sense, they reiterated the perspective of Gough [20] in cautioning against reducing the educational phenomenon to the characteristics of complex systems.

The concept of "wicked problems" was coined to refer to emergent problems with nonlinear, dynamic properties as "objects" of environmental education [23-26], and thus "complexity" has been relegated to a "simple" version, an adjective of the environmental problems understood as coupled social-ecological systems in the era of post-normal science and "risk society". "Wicked problems" are in their origin "issues highly resistant to resolution" [27], and in non-expert use, they are frequently reduced to those problems whose "solution is difficult to identify" due to their "high social complexity" [28].

With regard to learning and innovation, Wals, Lens, and Kupper [29] also worked through knowledge configurations, exploring the aggregation of knowledge levels through cases studies to understand "their key characteristics and the factors and guiding principles that contribute to their success or lack thereof" (p. 2). By raising the perspective of "hybrid configurations of knowledge" and "hybrid" learning, Stevenson at al. [23] sought to provide new types of learning that would enable, among other achievements, intercultural learning (p. 544). This framework has the potential to foster the imagination of other futures, but as long as it is framed within the usual contemporary questions of education for success and standing from the input and output model, knowledge configurations seem to be still "read" from a linear framework, which reduces the transformative potential of this proposal. 
While complexity science has advanced in terms of the knowledge of the structures of complex systems and the development of methodologies for their understanding, complex thinking is considered a method that makes it possible to describe knowledge networks, which, in the epistemological field, has implications both in the domain of socio-environmental phenomena as well as for current challenges in the field of education.

In line with these epistemological considerations and also searching for transformative practices, González-Gaudiano [30] questioned the educational implication of complex thinking from the Latin American context. He stated the necessity of constructing conceptual articulations that make it possible to account for environmental complexity in relation to the epistemology on which environmental knowledge is built and linked to positions of power as a condition to be able to construct educational discourses suitable for specific contexts. Complexity is then necessary both for the dislocation of the static points on which classical science has been sustained, and consequently, environmental education based on facts of science. It is also important for the appropriation of an anti-essentialist project that impacts the educational content "about" the environment. González-Gaudiano sought to summarize these perspectives in the following statement, "the conditions for the possibility of an education for our times, including environmental education, lie in the construction of open proposals, fractured proposals that do not claim to be constituted in universals." (p. 163).

The perspective of Gonzáles-Gaudiano [30] on complexity and its potential in the educational field has foundations in the Latin American Environmental Thought, which, in turn, is an heir of the critical pedagogy of Freire. Additionally, Enrique Leff, one of the main figures of the Latin American Environmental Thought tradition, considers the environment as "an epistemological concept, as an anchoring point outside the hegemonic system of the Universal. ( ... ) It could not be a paradigm that is absolutely external and untouched, but one that is forged in the territorialization of diversity, difference and otherness, and in the cultural knowledge that inhabits the territories of the South." [31] (p. 2-3).

With regard to the environment, Leff's position provides a different epistemological possibility, making reference to a new configuration with historical and territorial backgrounds that highlights difference and otherness as key concepts. From the South, we proposed complex thinking as a method that seeks to understand environmental configurations from the narratives of students in specific and significant contexts, such as their schools, neighborhoods, and cities. The objective then consisted of highlighting the meanings of the environment as a condition of those (and other) transformations, which suppose both a reformulation of the content of "environment" as well as the way in which such knowledge is configured. These transformations are part of the shared purpose of the authors in the North and South who are investigating the links between environment and education with a view towards social and environmental transformation, but also to an epistemological transgression that considers the ethical and political dimensions of such problems and their current requirements.

\section{Complex Thinking as a Method: Knowledge as an Intersubjective Experience}

Complex thinking considers knowledge as embedded in "interwoven" networks and emerging in the displacement between different levels of organization networks. At the same time, each of these levels can be identified as "complex" as they are all interrelated, allowing their conditions and contextualizing their limits [32].

For example, both the biological and social historical dimensions are part of the same network of knowledge, which implies that an idea takes place or exists not only inside the "head", as thought by reason alone, but also in the lived body $($ Leib). With complex thinking, the main idea is to understand that knowledge is not reduced to simple logical processes-whether inductive or deductive-but that it exists and is expressed and conceived in a mutual relationship and in a dynamic and adaptive intersubjective processes [33]. By understanding knowledge as an action, we recognize its dynamic character, and with it, the possible emergence of new meanings as new possibilities for action based on experiences. 
Now, this subject is no longer conceived as a thinking being (res cogitans) that is lonely and isolated from its condition of "being-in-the-world". Rather, there is a co-determination of the subject with himself/herself, with others, and with the world. Under this perspective, being a subject is understood as a plural experience of being-in-the-world, which means being in language, in history, and in life [34].

In the field of education, Davis and Sumara [35] proposed that the complexity approach provides a form of understanding that considers the simultaneities of a subject that are not usually addressed by other disciplinary discourses that have been adapted to refer to the educational phenomenon. One of the contributions of this complexity approach is the nested imaginary, which allows one to pay attention to both the subject-centered micro-perspective and the macro-perspective of the collective knowledge system. The knowledge network can then be characterized as a convergent dynamic between simultaneous phenomena, such as personal cognition, collective action, structures and institutions, and socio-historical knowledge, where each of these complex units becomes flexible and generative, allowing them to remain adjusted to changing and uncertain contexts in a permanent flow (pp. 91-92). This view coincides with that of Castoriadis [36], who proposed the concept of socio-historical knowledge production through the institution of society by its movements of adhesion, support, consensus, legitimacy, and belief as well as coercion and sanctions (p. 11).

All phenomena and complex systems adapt, and in the language of complexity, learning is understood as renegotiations between the perceived limits of individual knowledge and knowledge conceived as a social and collective experience [35]. In this way, knowledge corresponds to the continuous process through which the subject that knows and the knowledge itself are simultaneously redefined in their mutual relationship (p. 27).

Then, the emergence of meaning arises from the self-organization that comes from the continuous displacement and co-adaptation between levels of organization, where considering each phenomenon in itself is as important as considering the conditions of its emergence. From the educational perspective, this emergence can include motivation, enjoyment, cooperation, and collaborative activity [37] (p. 22).

In an effort to propose some levels of organization, phenomena, and co-adaptation in the educational field, Davis and Simtt [38] provided a diagram comprised of several co-related knowledge spheres. Between the sphere of subjective understanding and the sphere of socio-intersubjective knowledge, as we renamed it, there is the sphere of the collective classroom and the sphere that represents the curriculum or educational policy (Figure 1, adapted from Davis and Simtt [38] p. 296).

Based on the same interpretation, Davis and Sumara [35] also suggested that the outer spheres have been less challenged in educational research, whereas the inner spheres are seen as relatively easy to influence. Given these expectations, teaching is usually considered to involve the adaptation of personal understanding to established knowledge standards, ignoring the dynamic activity that is implied by the various spheres represented in the diagram (p. 91).

The nested spheres diagram implies co-determination, which does not include hierarchy or closure between the spheres. Under this framework, the spheres are not considered parts of an already determined whole, but rather, they are used to represent levels that facilitate the description of the proposed configuration.

The spheres themselves and the transitions between them imply the emergence of knowledge and meaning. The authors point out that complexity emphasizes the process of activating potentials in different spheres, which can help to trigger emergency processes involving more sophisticated possibilities of action. In this way, complexity allows us to approach learning as an intersubjective phenomenon where different levels intervene and interact. This served as a guide to understand the emergence of meaning throughout the conversations we had with students during this research. 


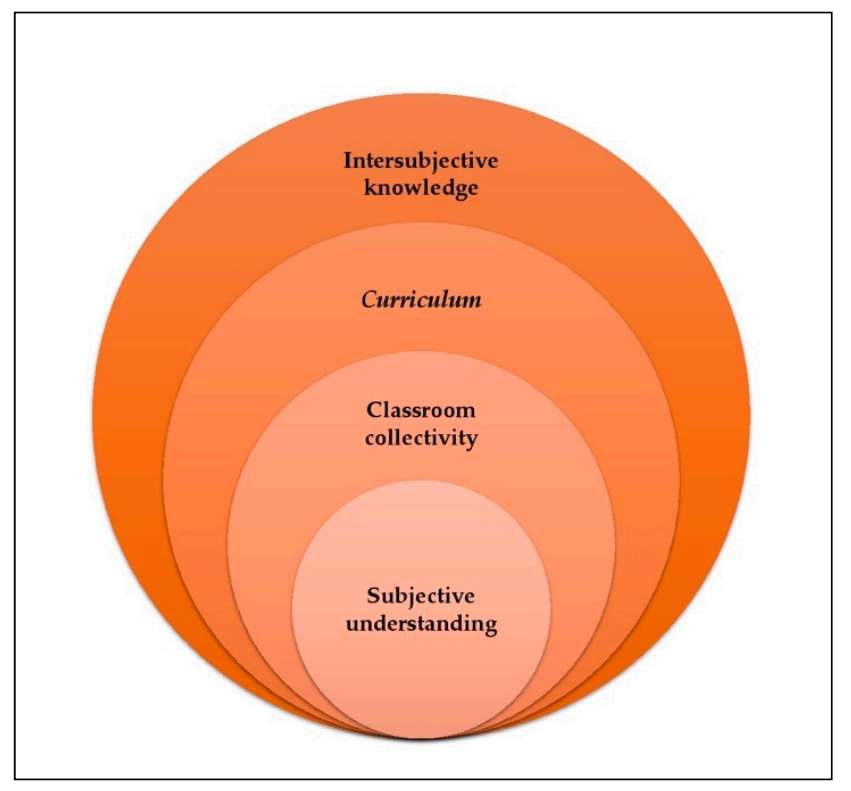

Figure 1. Intermediate spheres of complex knowledge.

\section{Questions and Methodology}

The purpose of this research was to unveil the dynamics of environmental-related knowledge configurations based on the experiences of disadvantaged young Chileans by interpreting the aspects revealed in the discussion concerning the students' perspectives on environmental issues and Climate Change.

The discussions among students were carried out within the framework of the international project "Youth and Climate Change" [39] which encourages students to interpret their environmental problems and address them using project-based methodology. In that process, student proposals emerged on different scales and were shared with school children from 20 countries.

The students who participated in this research were between 16 and 18 years old and attended public high schools in different peripheral municipalities of Santiago, Chile. In each school, discussion groups with six to eight participants were guided by a moderator who posed the following open questions: How does your community, school, family, neighborhood, and city experience and perceive Climate Change? What environmental problems affect them? How can we face these problems? What are the alternatives to address them?

Some of the students were participants in environmental brigades during and after school hours. All of the schools followed the national curriculum, which emphasizes Education for Sustainable Development through the National Policy of Education for Sustainable Development [40].

The discussions among students were interpreted through non-discrete categories that highlighted different moments that recognize the interactions and transitions between the subjective, intersubjective, and operational knowledge spheres of the socio-historical nature proposed by Davis and Sumara [35]. These transitions were interpreted as configurations of meaning and environmental knowledge that students are able to express from their "lived experience" at school.

In this study, the students' experiences were not fragmented by particular disciplinary epistemological and methodological frameworks, but rather, they were approached from a general yet concrete framework. Therefore, the design allowed us to make methodological decisions with relevance, since it is the method that manifests an epistemological way of inquiry that contextualizes the investigation techniques, and not the techniques that reduce the method to the results of its simple application [11]. 
Under this framework, the proposed categories were used to interpret ("read") the transversality of the dimension of place based on the intersubjective and social experiences of the students in their own context.

\section{The Voices of the Students: Environmental Knowledge Configurations}

Understanding and interpreting the discussions among students allowed us to explore the roads they travel in the configuration of knowledge, in this case, driven by reference to the environment.

The categories presented here are not empirical examples of a specific content, but rather, are descriptions of complex knowledge that is "interwoven" in students' own experiences and in their perceptions of the world in which they live. This sinuous, fragmented, and often interrupted path is fundamentally articulated by the method that underpins complex thinking. This "thinking", contrary to a simple analytical methodology, supposes an interpretation, a "reading" in an attempt to "listen" to even that which is not explicit in such knowledge experiences. Specifically, in this article, we propose a description of this itinerary using the theoretical-methodological contribution proposed by Davis and Simtt [38].

The first category is called "starting with oneself", where students give meaning to the environment in reference to actions at the individual level. In the second category, "construction of us", the transition is from the first sphere of subjective understanding to the intersubjective sphere of $u s$ in the classroom, school, and community, thus extending the limits of the environment configuration to collective action. A third level is recognized-always in relation to the first two-where it is possible to highlight the contribution of operational knowledge in this network, which in this specific case, was based on the concept of Climate Change exposed in the school curriculum. As a whole, the dynamic interactions of all of these levels is part of the knowledge itinerary configuration of the social and historical knowledge related to the environment, as revealed in this research.

\section{1. "Starting with Oneself", the Understanding of Oneself and the "Other"}

While interpreting the dynamics of the discussion groups concerning environmental issues, we observed a first stage that we called "starting with oneself". In this phase, students expressed their opinions from the "individual" context based on experiences in their own communities and developed a configuration of meaning characterized by the distance between the self and the "other". In this category, the understanding of the "self" is not an understanding of the individual, since the individual along with the "Other" belong to the same constitution of meaning and the same hermeneutical circuit of meaning [41].

This subjective and self-understanding, together with the ensuing awareness and action, is what allows young people to establish their positions with respect to a diverse group of others, as shown by the following quote:

"I find that first, if we want to change people, we have to start by changing ourselves. Instead of using words or speaking eloquently, we have to practice what we preach, because there is a big difference in walking the walk, and that starts with ourselves ..."

The participants spoke from themselves, and from a space that was their own and in which they lived, about their views and appropriations of the environment. From that level, meanings arose that were validated as catalysts of change in others, thus seeking to motivate them to carry out joint actions:

"... for example, if I want to see something nice in my house ... I can help by putting plants in flowerpots, so when people come over and see this they go 'this house is pretty!' ... and people start gradually realizing who makes the difference, and then others realize the same."

Instead of individualizing experiences, in this category, it is possible to see the transition from subjectivity (self) to the expression of socio-historical knowledge shared with others who inhabit it 
in a process of intersubjective configuration of the environment. The self and the Other-or oneself as another, as Ricoeur would say - are not opposites, but they are not the same either. The idea of transition emphasizes the interplay between these two, which involves subjective tensions, and at the same time, acts as an interpretative key to intersubjective action and knowledge [41].

\subsection{Intersubjectivity, the Construction of the "Us"}

At this specific level, there is a transition from " $\mathrm{I}$ " to " $\mathrm{us",}$, where a sense of community emerges and it can be characterized as a unit in action and in purpose. In this phase, students moved away from the subjective point of view to include others who also inhabited the school in the development of a community environmental project.

"We should start by raising awareness in young children, well in everyone, raising awareness from our experience or maybe inviting older children ... who can help us, especially [those] who have a more critical thinking ..."

One of the proposals that we observed in this phase was the sharing of knowledge and experiences with others by inviting them to participate in a collective process. The students proposed that awareness could be raised through critical reflection and by encouraging discussion among peers with a view to expanding alternatives. Debate and critical reflection were proposed as tools, emphasizing that the dynamic and adaptive interaction between this sphere and the previous one gives meaning to community actions regarding the environment.

"We have to debate and everyone should provide their point of view. Then we combine everything and reach a conclusion that everyone agrees on."

From these new shared meanings, an "us" began to consolidate, in which actions that respond to common objectives and proposals are explored; hence, negotiations are undertaken and a common view is shared. This new unit, always nourished by subjective understanding, is in simultaneous dynamic interaction with other spheres of knowledge such as educational policy, which contribute concepts and views with which they co-relate and adapt by configuring new meanings that transcend the boundaries of the school.

"We need to take action not only in school, but in the community, because we can see there is more and more construction ... and Santiago already reaches the highway, so we have to make sure our community has a plaza, and we care for that plaza ..."

Davis and Sumara [35] proposed an intermediate sphere of "intersubjectivity in the classroom", which we expanded in this research by adding the experiences outside of school where students give meaning to the environment (Figure 1). While students shape and extend a common place with others, causing the expansion of "us", other social actors become relevant in their shared configuration itinerary.

"Yesterday we went to a meeting at the municipality ... they made a matrix, for example: green areas, cleaning, education, infestations and ... on the other side they put the solutions. Yesterday we went to present solutions to these problems. The president of the environment [committee at school], the director, teachers from all the schools in the municipality and a student of the commission of each school attended. It went well."

In this case, students recounted their involvement in a participatory process on a local scale, which favored their own recognition as active social beings beyond the limits of the school. In these experiences with new "others", they gained new perspectives for action, and also new concepts such as "green areas" and "infestations", which acquire meaning in the intersubjective experience with other local actors and are based on common problems. 
However, not all experiences outside of school triggered feelings of satisfaction in students, so events that acquired meaning as experiences of exclusion and frustration appeared in the discussion: "If we go out and voice our concerns about the environment, they don't listen. Why? Because we are young and we don't know what we're doing ... so it's complicated to go out and think differently."

In this way, new meanings emerge that necessarily transcend operational knowledge "about the environment", and relations that constitute learning that surpass the distinction between the subject that knows and knowledge itself.

\subsection{Operational Knowledge}

In this third category, we sought to interpret the interaction of the spheres already raised by Davis and Sumara [35] and the contribution of the international curricular discourse present in the Chilean curriculum through concepts such as Climate Change. Operational knowledge is indeed social and historical, and in this context, represents the educational and social objectives that a particular society seeks to achieve (explicitly or implicitly).

Although students did not spontaneously mention the concept of Climate Change in the discussion, the moderator insisted on mentioning it.

Moderator: "What do you think climate change is?" ...

(...)

Juan: "The water droughts, the fires that are also happening because of trees being planted, the toxic [waste] ... I think climate change is half and half, we caused it, wrongfully or unconsciously, and it is also due to natural changes, so it is like a circle."

Vilma: "... also the view of the Chilean government on climate change ... the issue with the forest companies, they [the government] see it [climate change] as a simple change, something that must clearly happen ... but the forest companies also contribute to climate change."

Francisco: "Because of the drought."

Vilma: "Yes, that is one of the things that the forest companies cause, the degradation of the soil, when cutting a whole native forest there is a change in the climate, there is also a change in the population there."

Ana: "Also in species ..."

In this discussion among students, we observed that when introducing the perspective of Climate Change, there was a series of specific relations and concepts used that involved environmental operational language (toxic, drought, population, soil degradation, cutting of forest, native forest). The use of these concepts, also present in the curriculum, made references to environmental dynamics possible, at least for some students. Phenomena such as Climate Change and its incorporation into the educational policy, allowed them to recognize interrelations that went beyond their daily experience, which encouraged links with phenomena on larger scales. However, these references are not consolidated as knowledge (understood as possibilities for action) until they are re-linked to their common everyday experience, from which a process of reflection for action begins, which is fundamental for the emergence of alternatives to the crisis.

"I don't think there's a short-term solution ... but rather a long-term one. What is the point of someone coming to give you a lecture, of someone trying to raise your awareness, if in the end what makes a difference are the actions you take."

Again, action constituted the difference between the discourse and the possibilities of contributing to the (posed) problem of Climate Change. From our complex "reading" of the students' narratives and 
their particular itinerary, environmental knowledge was configured through intersubjective dynamics that have place as a condition of the possibility of collective action. Place appears as a condition of knowing as a whole and also in its "weave" (complexus), rather than as the idea of a structure with a static identity or one that is reduced to a single content or definition.

\section{Discussion: The Emergence of Place as a Plural Axis of Meaning}

Considering that environmental knowledge acquires meaning for students through place, it seems important to briefly distinguish our understanding of place with respect to other proposals in the educational field.

The discussion about place in the field of environmental education has an important background in multiple fields, including philosophy, psychology, critical theory, anthropology, and cultural geography. Specifically, there have been proposals of place-based education [42,43], situated pedagogy [44], place-based perceptual ecology [45], critical pedagogy of place [46-48], and critical theory of place-conscious education [47]. The perspectives of place that underlie these educational proposals have received diverse influences from the phenomenology approach of Heiddeger and Merleau-Ponty through the humanistic geography of Relph [49] and Tuan [50-52], among others authors.

In line with the objective of this paper, we highlight the contribution of the critical theory of place-conscious education [47] as it seeks to contribute to a culturally-responsive theory of environmental education by recognizing its distance from diverse practices of place-based education that have been instrumentalized to achieve outcomes associated with traditional schooling while silencing its political content (p. 95). For her part, McKenzie [53], influenced both by phenomenology and by a comprehension of place as a process—as proposed by Massey [54] — concentrated on pedagogical experiences and proposed other "places of pedagogy", highlighting learning "as taking place in between the thought and the sensed via a range of intersubjective experiences" [53] (p. 361). For McKenzie [53], "place" is the place of learning, so she proposed that the "where" of learning may occur in "particular physical places, but can also be in and of experiences of friendship, art, literature, irony, cultural difference, community." (p. 361). In this way, she challenged educational objectives beyond "awareness" and "deeper connection to place" and emphasized others such as learning and cultural training from the collective commitment of the students.

From this perspective, place loses its central category as a noun, which is still present in the formulation of Gruenewald, according to whom places are profoundly pedagogical [46], and the focus is placed on "where" intersubjective learning takes place. All learning experiences have place as a condition, in a process where it is produced and producing.

Hence, by re-interpreting the students' discussions from the perspective of complex thinking, we observed relationships that indistinctly intertwined spheres of knowledge and actions. When students were encouraged to discuss their perspectives on the environment, these were expressed particularly in terms of the intersubjective experience of place, which manifests itself both as a condition and as a "product" generated from the relationships of "lived space".

Place is, thus, the space that students inhabit and the space of a communitarian "us", where their questions, desires, and proposals are expressed, and where they formulate their possibilities. According to Tuan, the distinction between space and place is correlated: "If space is what allows movement, then place is pause, each pause in the movement makes it possible for location to become place" [50] (p. 6). It is in this movement, and especially in the condition of possibility, where the environment acquires meaning through the intersubjective experiences of the students. Along this same line, for Relph [49], consciousness is not only about something, but something in its place.

Following this line of argument, place is not only relevant to the configuration of environmental knowledge, but is a dimension that questions the dualities of human being-nature, subject-object, and with it the essentialist paradigm, which directly impacts the school institution as it has been conceived until today in the West. 
The hierarchies inside and outside the school are also tested as well as their usual times and spaces. This deconstructs the traditional structure of disciplinary knowledge, which in the contingency and practice of doing so requires the integration of knowledge and actions. As the students themselves acknowledged:

"... everything goes hand in hand: home, the school, the culture, the arts, everything contributes to shaping a cultured person, someone who knows not to throw garbage, who knows the environment has to be cared for ... I think everything is connected".

According to the students' voice, environmental knowledge allows more than one rationality. It is not only based on the facts of science, neither is it necessarily linked to pro-environmental attitudes derived from normative approaches to environmental education, nor is it just a product of a constructive process of the accumulation of experiences on the part of the individual in their environment. In this sense, the meanings of the environment include both those of the phenomenon and the socio-historical conditions of its emergence.

The configuration of place from the students' perspective not only refers to the essence of the being-in-the-world in general, but also to the emplaced $u$ s, from where the question of the becoming of place emerges, giving meaning to the complementarity between the subject and the world, and opening the possibilities for action.

Through their particular place, students showed a critical view and a desire for transformation, appropriation, and projection, which seems suggestive when national statistics show that $85 \%$ of the young population of low socioeconomic status are hardly or not at all interested in politics [55]. However, the students who participated in this research did not cease to pose questions and possibilities. Place is thus a key dimension of meaning, action, and transformation, as stated in the following quote:

\section{"... they are building a school near my house, and (... ) sometimes I wonder what I would build in that school?"}

Therefore, place is also the condition for possibilities and dreams. A way of interpreting the place-related environmental configurations included in this article is the proposal of "environment as potential" [56]. From his experience in different contexts, Sauvé [5,56] discussed environmental perspectives, among which the environment as a "community project stands out as relevant and emphasized as the place where we are involved". Place is also a political concern of the community as well as the focus of critical analysis, where evolution requires a supportive and democratic attitude [56] (p. 13). These characteristics are different from other environmental perspectives that consider the environment as nature, resources, or in terms of its problematic character [56] and involve other meanings rooted in other experiences, which undoubtedly also contribute to the configuration of knowledge presented in this article from what we have called the sphere of operational knowledge.

Furthermore, an appropriate contribution that facilitates interpretation from the socio-historical context is the critical pedagogy of Paulo Freire, which has been one of the pillars of environment-related education and the Latin American Environmental Thought, as he proposed a powerful link between education and social problems. The critical pedagogy of Paulo Freire intends to respond to the realities in which students and workers are situated [57], linking knowledge, understanding, experience, school, and the environment in a collective and supportive school climate [58]. However, in the Chilean context, the tradition originated in the 1960s that links environmental education with the resolution of social problems at the local community level, is undervalued in the new educational framework proposals $[59,60]$.

Reading the perspectives of students in their historical and social contexts allowed us to make some comments. The project of place that students actively seek to build is a project with open objectives. The search is not necessarily to respond to "environmental issues", as already established by environmental science or social scientists, but to consider place as a fundamental condition to "rehearse 
other ways of thinking-feeling-acting" [31] (paragraph 60) that are not always valued in traditional educational contexts marked by accountability.

With place as the axis of meaning, the politics of place involve explicitly asking about the construction of that place [61], since, as posed by McKenzie [53], "The 'where' of the who of the subject that comes to education, cannot be assumed or fully anticipated, and is certainly critical in the learning that takes place there." (p. 369). Following these perspectives, a version of place as a condition of being-in-the-world is complemented by a framework that recognizes the relevance of differences, making it possible to consider different dimensions of place in the formulation of educational projects for the global scale.

\section{The Environment in Its Diverse and Plural Dimensions}

In this journey, which included using a method to "read" the configuration of environmental knowledge in a specific context, and whose contribution is a perspective that highlights place as a dimension of meaning in its intersubjective configuration, we reflect on the challenge of "Global Education". It seems to us that this can occur only through the possibility of recovering place from its usual problematic conceptualization of being tied to a chain of static, closed, and immobile meanings to unite it with other perspectives related to openness, heterogeneity, and life, which reconnect and include place in the new conceptualizations of politics and the political [54] (p. 19). Challenging the limits and permanence of place makes it possible to think about the challenge of global projects, which involves recognizing knowledge as a "weave", always in context, and place, conceived as a plural experience of meaning and embodied in different projects of place that, as a whole, can constitute a "unique assemblage" [62] without forgetting the "materiality" of the meeting points overlaid onto real bodies and geographies [63] (p. 216).

Problematically, thinking globally is a concept that has circulated in the field of environmental education for decades and remains poorly theorized and examined [14] (p. 54). Gough [14] suggested that if the curriculum raises consensus regarding the environment and assumes that we can make sense of it transculturally by proposing a "universal 'we'" in the face of global environmental problems and their solutions, it runs the risk of remaining peripheral and losing its ability to contribute elements to the configuration of meaning. The contribution of the international environmental discourse should not be minimized, since, for example, the concept of Sustainable Development can contribute to configure different approaches to the link between development and sustainability through local and global perspectives [14].

The question that arises is how educational projects are able to appreciate the plurality of the dimensions of meaning offered by place. The configuration of meanings on a global scale involves expanding intersubjectivity to wider communities and therefore, other experiences and traditions of knowledge, challenging the configuration of another place, and at the same time, the educational possibilities of a new space to give meaning to.

With the aim of giving value to both what was expressed and what was not made explicit by the students, we consider it important to highlight that even though the students were directly asked to share their views on "Climate Change", the references to this concept were very sporadic, and during the discussions, there were no mentions from the students of concepts such as "sustainability" or "sustainable development". In this sense, these concepts associated with the global environmental discourse, which are part of the Education for Sustainable Development curriculum promoted by UNESCO and at the local level by the National Policy of Education for Sustainable Development [40], do not seem to have acquired a dynamic that highlights them as axes of meaning yet. A possible interpretation is that these concepts are not yet part of the project of place held by the students today, which are closely related to the axes of meaning that have developed in traditional environmental education in our country, characterized by the resolution of social problems at the local and community levels [60].

It is worth clarifying that our interpretation does not deny the existence of Climate Change in the local context, but rather, aims to highlight the configurations that account for this phenomenon from a 
localized perspective, configured in the dynamic processes between different spheres of knowledge through which meaning emerges and with it, alternatives for action emerges.

In highlighting the value of place, Relph [49] provided the concept of placelessness, which is defined as "the casual eradication of distinctive places and the making of standardized landscapes that results from an insensitivity to the significance of place." [49] (p. ii). In the context of the educational field, Gruenewald [46] proposed that denying the specificity of place would have a high pedagogical impact by obscuring the relations between place, culture, and education; freeing people from their responsibilities as builders of place; and legitimizing the ideologies behind the construction of places [46] (p. 628). According to our framework, the denial of place would deny the capacity of the subject to act due to the lack of shared meaning. This is not to say that students are disconnected from place, quite the opposite, it is, for instance, the national and international educational policy needs to recognize the specific configuration of each place, not only from a rhetorical perspective but from the intersubjectivities that allow the becoming of place. The preeminence of place as a plural axis of meaning allows us to understand the real challenges posed by environment-related education, where place (as "lived space") needs to be considered as a fundamental dimension of the educational experience.

Conceiving environmental knowledge as an interconnected web is an essential point of departure for democratic discussions that value differences in local environmental perspectives. Those differences constitute diverse knowledge configuration itineraries regarding environmental issues that adapt through interrelation with a new level of "global" intersubjectivity that emerges in democratic discussion and expresses the desires, challenges, and utopias of a common future. A contribution to this perspective comes from Latin American Environmental Thought, where many important perspectives in relation to environmental knowledge have been highlighted as it is considered as dialogue of knowledge in the same construction of environmental complexity that "... emerges in the proliferation and the crossing of identities (... ), it is the opening of the being constituted by its history towards the unprecedented and the unexpected; towards an utopia rooted in the being and in the real, built from the potentials of nature and the senses of culture." [64] (paragraph 31). Within that framework, we therefore argue that global education projects must be structured upon differences, as it is in those differences that the possibility of generating knowledge as action and as meaning is found.

Fortunately, today, it is possible to recognize educational practices that seek to generate conditions for democratic discussion at a global level, where place is described from students' voices as a horizon of meaning on a scale greater than that of the school and the local community itself. These transgressive practices allow us to configure meanings in an extended community and to incorporate other experiences into a common revisited experience, where identities move towards the uncertain in the recognition of shared utopias.

Author Contributions: Conceptualization, A.C.-M. and L.F.-G.; methodology, A.C.-M.; software, A.C.-M.; investigation, A.C.-M. and L.F.-G.; Writing-Original Draft preparation, A.C.-M.; Writing-Review and Editing, L.F.-G.; project administration, L.F.-G.; funding acquisition, L.F.-G.

Funding: This research was part of the "Youth and Climate Change" program which was sponsored by the Edgar Morin Center (EHESS, Paris, France), the International Research Institute on Civilization Policy (IIRPC, Poitiers, France), the International Center for Comparative Environmental Law and the Faculty of Law and Economics of Limoges, the French National Museum of Natural History, and the Universite Paul Sabatier Toulouse III. In Chile, this program was developed with the sponsorship of Pontificia Universidad Católica de Chile (Faculty of Education and Department of Ecology and Institute of Ecology and Biodiversity), the CONYCIT-Explora Program, and MINEDUC. In addition, this paper was part of the theoretical framework of two research projects: 1 . Regular FONDECYT Project. Flores, Luis M. (2013-2015). School climate and knowledge management in secondary education. Towards a pedagogical quality policy for the educational institution in Chile. (No. 1130449). 2. VRI-UC Project. Flores, Luis M. (2017-2018) Complex knowledge structures in Geography and Biological Sciences. Toward the formulation of an interdisciplinary program in sustainable development education.

Acknowledgments: We would like to thank those who inspired this article, the researchers in the field of education and complex thinking who have posed the question about the theories and practices in environmental education.

Conflicts of Interest: The authors declare no conflict of interest. 


\section{References}

1. Bertrand, Y.; Valois, P. École et Sociétés; Éditions Agence d'Arc: Montreal, QC, Canada, 1992.

2. Hart, P. Teachers' Thinking in Environmental Education. Consciousenes and Responsibility; Peter Lang: New York, NY, USA, 2003.

3. Sandell, K.; Öhman, J.; Östman, L. Education for Sustainable Development: Nature, School and Democracy; Studentlitteratur: Lund, Sweden, 2005.

4. Sauvé, L. Una Cartografía de Corrientes en Educación Ambiental. In A Pesquisa em Educação Ambiental: Cartografias de Uma Identidade Narrativa em Formação; Sato, M., Carvalho, I., Eds.; Artmed: Porto Alegre, Rio Grande do Sul, Brasil, 2004. Available online: http://www.ecominga.uqam.ca/PDF/BIBLIOGRAPHIE/ GUIDE_LECTURE_3/1/2.Sauve.pdf (accessed on 5 April 2017).

5. Sauvé, L. Exploración de la Diversidad de Conceptos y de Prácticas en la Educación Relativa al Ambiente. In Seminario Internacional La Dimensión Ambiental y la Escuela; Ministerio de Educación Nacional: Bogotá, Colombia, 1994.

6. Scott, W.; Gough, S. Sustainable Development and Learning: Framing the Issues; RoutledgeFalmer: London, UK, 2003.

7. Sterling, S. Higher Education, Sustainability, and the Role of Systemic Learning. In Higher Education and the Challenge of Sustainability; Corcoran, P.B., Wals, A.E.J., Eds.; Kluwer Academic Publishers: Dordrecht, The Netherlands, 2004; pp. 49-70.

8. Gough, N. Rethinking the subject: (De)constructing human agency in environmental education research. Environ. Educ. Res. 1999, 5, 35-48.

9. Gough, N. Surpassing our own histories: Autobiographical methods for environmental education research. Environ. Educ. Res. 1999, 5, 407-418. [CrossRef]

10. Gough, N. Complexity Reduction in Outdoor and Environmental Education: By Whom, for Whom, and in Whose Interests? In Proceedings of the Fourth International Outdoor Education Research Conference, Victoria, Australia, 15-18 April 2009.

11. Morin, E. La Méthode I; Seuil: Paris, France, 2008.

12. Merleau-Ponty, M. Phénoménologie de la Perception; Gallimard: Paris, France, 1945.

13. Sund, P.; Lysgaard, J.G. Reclaim “Education” in Environmental and Sustainability Education Research. Sustainability 2013, 5, 1598-1616. [CrossRef]

14. Gough, N. Thinking Globally in Environmental Education: Implications for Internationalizing Curriculum Inquiry. In International Handbook of Curriculum; Pinar, W.F., Ed.; Lawrence Erlbaum Associates: Mahwah, NJ, USA; London, UK, 2003; pp. 53-72.

15. Biesta, G.; Osberg, D. Complexity, Education and Politics from the Inside-Out and the Outside-In. In Complexity Theory and the Politics of Education; Biesta, G., Osberg, D., Eds.; Sense Publishers: Rotterdam, The Netherlands, 2010; pp. 1-2.

16. Biesta, G. Learning Democracy in School and Society: Education, Lifelong Learning, and the Politics of Citizenship; Sense Publishers: Rotterdam, The Netherlands, 2011.

17. Biesta, G. The Beautiful Risk of Education; Paradigm: Boulder, BC, Canada; London, UK, 2014.

18. Osberg, D.; Biesta, G.J.J.; Cilliers, P. From Representation to Emergence: Complexity's Challenge to the Epistemology of Schooling. In Complexity Theory and the Philosophy of Education; Mason, M., Ed.; Wiley-Blackwell: Oxford, UK, 2008.

19. Osberg, D.; Biesta, G. Complexity, Knowledge and the Incalculable: Epistemological and Pedagogical Implications of 'Strong Emergence'. In Proceedings of the Complexity Science and Educational Research Conference, Canada, Chaffey's Locks, ON, Canada, 30 September-3 October 2004; pp. 207-227.

20. Gough, N. Complexity, Complexity Reduction, and 'Methodological Borrowing' in Educational Inquiry. In Complexity, Chinese Culture, and Curriculum Studies; E.C.N.U., Ed.; Institute of Curriculum and Instruction: Shanghai, China, 2010.

21. Wals, A.E.J.; Rodela, R. Social learning towards sustainability: Problematic, perspectives and promise. Njas-Wagening. J. Life Sci. 2014, 69, 1-3. [CrossRef]

22. Wals, A.E.J.; Corcoran, P.B. Learning for Sustainability in Times of Accelerating Change; Academic Publishers: Wageningen, The Netherlands, 2012. 
23. Wals, A.E.J.; Stevenson, R.B.; Brody, M.; Dillon, J. Tentative Directions for Environmental Education Research in Uncertain Times. In International Handbook of Research on Environmental Education; Stevenson, R.B., Brody, M., Dillon, J., Wals, A.E.J., Eds.; AERA: New York, NY, USA; London, UK, 2013; pp. 542-547.

24. Lotz-Sisitka, H.; Wals, A.B.J.; Kronlid, D.; McGarry, D. Transformative, transgressive social learning: Rethinking higher education pedagogy in times of systemic global dysfunction. Curr. Opin. Environ. Sustain. 2015, 16, 73-80. [CrossRef]

25. Dillon, J.; Stevenson, R.B.; Wals, A.E.J. Special section: Moving from citizen to civic science to address wicked conservation problems. Conserv. Biol. 2016, 30, 450-455. [CrossRef] [PubMed]

26. Stevenson, R.B.; Wals, A.E.J.; Dillon, J.; Brody, M. An Orientation to Environmental Education and the Handbook Introduction. In International Handbook of Research on Environmental Education; Stevenson, R.B., Brody, M., Dillon, J., Wals, A.E.J., Eds.; AERA: New York, NY, USA; London, UK, 2013; pp. 1-6.

27. Rittel, H.W.J.; Webber, M.M. Dilemmas in a general theory of planning. Policy Sci. 1973, 4, 155-169. [CrossRef]

28. Australian Government. Tackling Wicked Problems: A Public Policy Perspective; Australian Public Service Commission: Canberra, Australia, 2007.

29. Wals, A.E.J.; Lans, T.; Kuer, H. Blurring the boundaries between vocational education, business and research in the agri-food domain. J. Vocat. Educ. Train. 2012, 64, 3-23. [CrossRef]

30. González-Gaudiano, E. Complexity in environmental education. Educ. Phiios. Theory 2001, 33, $153-166$. [CrossRef]

31. Leff, E. Pensamiento Ambiental Latinoamericano: Patrimonio de un Saber para la Sustentabilidad. In Proceedings of the VI Congreso Iberoamericano de Educación Ambiental, San Clemente de Tuyú, Argentina, 16-19 September 2009.

32. Davis, B.; Sumara, D. Complexity as a theory of education. Transnatl. Curric. Inq. 2009, 5, 32-44.

33. Flores, L.M. La Cuestión del Clima y el Espacio Escolar: Lineamientos y Proyecciones Pedagógicas. In El Factor Invisble: Estética Cotidiana y Cultura Visual en el los Espacios Escolares; Errázuriz, L.H., Ed.; Consejo Nacional de la Cultura y de las Artes: Santiago, Chile, 2015; pp. 101-109.

34. Maturana, H.; Varela, F.J. L'arbre de la Connaissance; Addison-Wesley: Paris, France, 1994.

35. Davis, B.; Sumara, D. Complexity and Education: Inquiries into Learning, Teaching and Research; Routlege: New York, NY, USA; London, UK, 2006.

36. Castoriadis, C. El Campo de lo social histórico ESTUDIOS. filosofía-historia-letras 1986. Available online: https://www.infoamerica.org/teoria_articulos/castoriadis02.pdf (accessed on 2 October 2017).

37. Morrison, K. Educational Philosophy and the Challenge of Complexity Theory. In Complexity Theory and the Philosophy of Education; Mason, M., Ed.; Wiley-Blackwell: Hoboken, NJ, USA; Oxford, UK, 2008; pp. $16-31$.

38. Davis, B.; Simmt, E. Mathematics-for-teaching: An ongoing investigation of the mathematics that teachers (need to) know. Educ. Stud. Math. 2006, 61, 292-315. [CrossRef]

39. Youth and Climate Change. Available online: http://www.globalyouthclimatepact.org/ (accessed on 27 December 2018).

40. Ministerio de Medio Ambiente, M. Política Nacional de Educación para el Desarrollo Sustentable; MMA: Santiago, Chile, 2009.

41. Ricoeur, P. Soi-Même Comme un Autre; Seuil: Paris, France, 1990.

42. Gruenewald, D.A.; Smith, G. Introduction: Making room for the local. In Placebased Education in the Global Age; Gruenewald, D.A., Smith, G.A., Eds.; Lawrence Erlbaum: New York, NY, USA, 2008; pp. xiii-xxiii.

43. Sobel, D. Place-Based Education: Connecting Classrooms and Communities; The Orion Society: Great Barrington, MA, USA, 2005.

44. Kitchens, J. Situated pedagogy and the situationist international: Countering a pedagogy of placelessness. Educ. Stud. 2009, 45, 240-261. [CrossRef]

45. Thomashow, M. Bringing the Biosphere Home: Learning to Perceive Global Environmental Change; The MIT Press: Cambridge, MA, USA, 2002.

46. Gruenewald, D.A. Foundations of place: A multidisciplinary framework for place-conscious education. Am. Educ. Res. J. 2003, 40, 619-654. [CrossRef]

47. Greenwood, D.A. A Critical Theory of Place-Conscious Education. In International Handbook of Research on Environmental Education; Stevenson, R.B., Brody, M., Dillon, J., Wals, A.E.J., Eds.; AERA: New York, NY, USA; London, UK, 2013; pp. 93-100. 
48. Greenwood, D.A. A critical pedagogy of place: From gridlock to parallax. Environ. Educ. Res. 2008, 14, 336-348. [CrossRef]

49. Relph, E. Place and Placelessness; Pion: London, UK, 1976.

50. Tuan, Y.-F. Space and Place: Humanistic Perspective; University of Minnesota Press: Minneapolis, MN, USA, 1977.

51. Tuan, Y.-F. Topophilia: A Study of Environmental Perception, Attitudes, and Values; Prentice-Hall: Englewood Cliffs, NJ, USA, 1974.

52. Tuan, Y.-F. Geopiety: A theme in man's attachment to nature and to place. In Geographies of the Mind; Lowenthal, D.B.M., Ed.; Oxford University Press: New York, NY, USA, 1975; pp. 44-56.

53. McKenzie, M. The places of pedagogy: Or, what we can do with culture through intersubjective experiences. Environ. Educ. Res. 2008, 14, 361-373. [CrossRef]

54. Massey, D. For Space; Sage: London, UK, 2005.

55. INJUV. Octava Encuesta Nacional de Juventud 2015; Instituto Nacional de la Juventud: Santiago, Chile, 2017.

56. Sauvé, L. Environmental Education and Sustainable Development: A Further Araisal. Can. J. Environ. Educ. 1996, 1, 7-34.

57. Freire, P. Pedagogía del Oprimido, 2nd ed.; Siglo XXI: Madrid, Spain, 2005.

58. Freire, P. La Educación en la Ciudad, 3rd ed.; Siglo XXI: Coyoacán, Mexico, 2005.

59. Squella, M.P. Environmental Education to Environmental Sustainability. Educ. Phil. 2001, 33, $217-230$.

60. Muñoz-Pedreros, A. La educación ambiental en Chile, una tarea aún pendiente. Ambiente Soc. 2014, 17, 177-198. [CrossRef]

61. Massey, D. The world we're in: An interview with Ken Livingstone. Sound A J. Politics Cult. 2007, 36, 11-25.

62. Casey, E. How to get from Space to Place in a Fairly Short Stretch of Time: Phenomenological Prolegomena. In Senses of Place; Feld, S., Basso, K., Eds.; School of American Research Press: Santa Fe, NM, USA, 1996; pp. 13-52.

63. Mckenzie, M. Pedagogical Transgression: Toward Intersubjective Agency and Action. In Fields of Green: Restorying Culture, Environment, and Education; McKenzie, M., Hart, P., Bai, H., Jickling, B., Eds.; Hampton Press Inc.: Cresskill, NJ, USA, 2009; pp. 211-224.

64. Leff, E. La Complejidad Ambiental. 2007. Available online: http://polis.revues.org/4605 (accessed on 27 October 2017).

(C) 2019 by the authors. Licensee MDPI, Basel, Switzerland. This article is an open access article distributed under the terms and conditions of the Creative Commons Attribution (CC BY) license (http://creativecommons.org/licenses/by/4.0/). 